\title{
Patient's Perception of Pharmaceutical Care Services; Challenges and Improving in Saudi Arabia
}

\begin{abstract}
Yousef Ahmed Alomi* ${ }^{\text {ID, }}$, The
Former General Manager of General Administration of Pharmaceutical Care and Head,

National Clinical pharmacy, and Pharmacy Practice and Pharmacy R \& D Administration, $\mathrm{MOH}$, Riyadh, Saudi Arabia.

Abeer Hussin Almasoudi, Director, Administration of Research and Studies, Ministry of Health, Tabuk, Saudi Arabia.
\end{abstract}

Sarah Abdullah Al-Hathlool, Clinical Pharmacy Staff, General Administration of Pharmaceutical Care, Ministry of Health, Riyadh, Saudi Arabia

Maryam Ibrahim Almulhim, Clinical Pharmacy Staff, General Administration of Pharmaceutical Care, Ministry of Health, Riyadh, Saudi Arabia.

Yousef Aboshalaf,

Head of Pharmacy Services King Fahad

Hospital, Alhasa, Saudi Arabia.

Mytham Al-Ethan, Assistant Head

of Pharmacy Services, King Fahad Hospital, Alhasa, Saudi Arabia.

\section{Correspondence:}

Dr. Yousef Ahmed Alomi, The Former

General Manager of General Administration of Pharmaceutical Care Head, National Clinical Pharmacy and Pharmacy Practice, Head, Pharmacy R\&D Administration, Ministry of Health, P.O.BOX 100, Riyadh 11392, Riyadh, SAUDI ARABIA.

Phone no: +966504417712

E-mail:yalomi@gmail.com

Received: 13-02-2019;

Accepted: 29-04-2019

Copyright: $($ ) the author(s), publisher and licensee International Journal of Pharmacology and Clinical Sciences. This is an open-access article distributed under the terms of the Creative Commons Attribution Non-Commercial License, which permits unrestricted non-commercial use, distribution, and reproduction in any medium, provided the original work is properly cited.

This is an open access article distributed under the terms of the Creative Commons Attribution-NonCommercial-ShareAlike 4.0 License

Access this article online

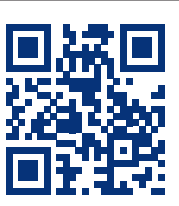

www.ijpcs.net

DOI:

10.5530/ijpcs.2019.8.32

\begin{abstract}
Purpose: To explore the patient's perception of Pharmaceutical care services; challenges and developments in Saudi Arabia. Methods: It is a 4-months cross-sectional survey of patient perception of pharmacists. The survey consisted of two-part demographic information and second part forty-nine questions divided into four domains. It included domain 1: Patient general perception of pharmacist domain 2: patients perception of pharmaceutical care services, domain 3: patient perception of visiting ambulatory care and domain 4: Patient's perception of the pharmacist's relationship and counseling. The 5-point likert response scale system was used. The questions were open and closed-ended. The survey was distributed through social media and as a 500-bed general hospital in Alhassa region, an ambulatory care pharmacy. The authors did the patients interview with electronic survey documentation. The survey was made an electronic format and it analyzed domain two about patient perception of pharmaceutical care services; challenges and developments in Saudi Arabia through the survey monkey system. Results: The total responders were 617 patients. Of those, $536(87.7 \%)$ was Saudi and 75 (12.3\%) was non-Saudi. The gender distribution $457(74.1 \%)$ were females and $160(25.9 \%)$ were males. The majority of patients visited the pharmacy in the past 12-months was $222(36 \%)$ more than ten times while $122(19.8 \%)$ attended (5-9 times). Most of the patient visited the pharmacy at evening 395 (64.6\%). Most of the patients' 481 (83.5\%) spent less than $11 \mathrm{~min}$ with the pharmacist. The most pharmaceutical care services provided to patients were dispensing of prescribed medication 390 (70.8\%), medication consultation 262 (47.5\%), dispensing of non-medications, supplements 233 (42.3\%) and dispensing of over the counter medications 229 (41.6\%). The high scores of the pharmaceutical care services provide to the patients were in private's hospitals (3.71) and community pharmacies (3.63). The most current experience of perception and challenges with high propriety scores were some pharmacy crowding, medication labels missed and patient privacy missed. The most future perception suggestion with high propriety and opportunity scores were published the pharmacy location through social media and implementation of adverse drug reaction reporting for patients. Conclusion: Patients' perception is a crucial tool to improve pharmaceutical care. Monitor implementation of the patient medication education system with private places, monitoring of drug-related problems will support the future vision of patient perception and attitude towards the pharmacist.
\end{abstract}

Keywords: Patient, Perception, Pharmaceutical Care, Challenges, Saudi Arabia.

\section{INTRODUCTION}

The role pharmacist is providing the pharmaceutical care. Most of the pharmacy organizations stated that is sentences and highly recommended to follow that is guidelines. ${ }^{[1-3]}$ However, what did the pharmaceutical care provided to the patient what did the patient get the benefits of the concept? What is the patient perception of implementation of pharmaceutical care? Several studies measure the level of pharmaceutical care services in the wide world and Saudi Arabia. ${ }^{[4-8]}$ So, what is current experiences and challenges perception of pharmacy services and what is the best pharmacy services provided under the government or private sectors. Most of those questions discussed in several studies worldwide with different perception, current experience and future expectations. ${ }^{[9-11]}$ It is hard to find an investigation about the patient perception of pharmaceutical services at local study site or Gulf and
Middle East countries. The objective of the study was to explore the patient perception of pharmacist, pharmacy services, challenges and development in the Kingdom of Saudi Arabia.

\section{METHODS}

It is a 4-months cross-sectional survey of patient perception of pharmacists. The survey consisted of two-part demographic information and second part forty-nine questions divided into four domains. It included domain 1: Patient general perception of pharmacist domain 2: patients; perception of pharmaceutical care services, domain 3: patient perception of visiting ambulatory care and domain 4: Patients' perception of pharmacist's relationship and counseling. The 5-point likert response scale system was used. The questions were open and closed-ended. The propriety 
and opportunities scores of 5-point scales was used for the current and future perception and challenges. The survey was distributed through social media and at a 500-bed general hospital in Alhassa region at ambulatory care pharmacy. The hospital was accredited by Saudi Center for Healthcare organization (CBAHI) and Joint Commission on Hospital Accreditation from the United States of America (USA). ${ }^{[12,13]}$ The hospital had several departments, including the adults internal medicine, adult surgery, pediatrics, obstetrics and gynecology. It had adults, pediatrics and neonatal critical care, with the separated nursing unit in addition to medical and surgical ambulatory care clinics. The pharmacy departments distribute the medication through the unit dose system according to CBAHI standards and American Society of Health-System standards. Also, the pharmacy had inpatient pharmacy, outpatient pharmacy and intravenous admixture services with professional Total Parenteral Nutrition (TPN). The clinical pharmacy services covered critical care units, internal medicine, drug information center, patient-counseling services and medication safety program. The authors did the patients interview with electronic survey documentation. The survey was made an electronic format and it analyzed domain two about patients' perception of pharmaceutical care services; challenges and developments in Saudi Arabia through the survey monkey system.

\section{RESULTS}

The total responders were 617 patients. Of those, 536 (87.7\%) was Saudi and 75 (12.3\%) was nonSaudi. The gender distribution 457 (74.1\%) were females and 160 (25.9\%) were males. The majority of them in age (18-44) $84.1 \%$ and located at Alhasa Region 255 (41.7\%), Riyadh Region 150 (24.55\%) and East Province region 144 (23.56\%). The most educational level of the responders were Bachelor degree 395 (64.4\%), followed by high school level 95 (15.5\%). The majority of patients visited the pharmacy in the past 12-months was 222 (36\%) more than ten times, while 122 (19.8\%) attended (5-9 times). Most of the patients had the follow-up visits 192 (81.70\%), while 43 (18.30\%) was the First visit. Most of the patient visited the pharmacy at evening 395 (64.6\%). Most of patients 481 (83.5\%) spent less than 11 min with the pharmacist (Table 1). The most pharmaceutical care services provided to patients were dispensing of prescribed medication 390 (70.8\%), medication consultation 262 (47.5\%), dispensing of non-medications, supplements 233 (42.3\%) and dispensing of over the counter medications 229 (41.6\%) (Table 2). The high scores of the pharmaceutical care services provide to the patients were in private's hospitals (3.71)

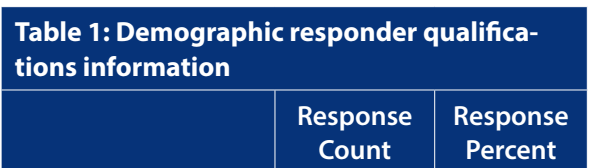

\section{Sex}

Female

457

$74.07 \%$

Male

160

$25.93 \%$

Answered question

617

Skipped question

0

Nationality

Saudi

536

$87.73 \%$

Non-Saudi

Answered question

75

$12.27 \%$

Skipped question

Age

$<18$

$18-29$

$30-44$

$45-59$

$60+$

Answered question

Skipped question

Qualification of the responders

Doctorate degree

Master degree

Bachelor Degree

Diploma

High school

Intermediate School

Primary School

Not educated

Answered question

Skipped question

Type of visit

First visit

Follow up

Answered question

Skipped question

In the last 12 months,

the number of times

visited the pharmacy

None

1 time

2

3

4

5 to

5 to 9

10 or more times

$64.44 \%$

$7.50 \%$

$15.50 \%$

$4.73 \%$

$0.82 \%$

$0.16 \%$

613

4

Count Percent

$192 \quad 81.70 \%$

235

2

Count Percent

\begin{tabular}{l|l}
23 & $3.73 \%$
\end{tabular}

$\begin{array}{ll}40 & 6.49 \%\end{array}$

60
$56.74 \%$

$56 \quad 9.09 \%$

\begin{tabular}{l|l}
93 & $15.10 \%$
\end{tabular}

$122 \quad 19.81 \%$

\begin{tabular}{l|l}
222 & $36.04 \%$
\end{tabular}

\begin{tabular}{|c|c|c|}
\hline Answered question & 616 & \\
\hline Skipped question & 1 & \\
\hline $\begin{array}{l}\text { Time of Visiting the } \\
\text { Pharmacy }\end{array}$ & $\begin{array}{c}\text { Response } \\
\text { Count }\end{array}$ & $\begin{array}{c}\text { Response } \\
\text { Percent }\end{array}$ \\
\hline Morning & 116 & $18.99 \%$ \\
\hline Evening & 395 & $64.65 \%$ \\
\hline Night & 100 & $16.37 \%$ \\
\hline Answered question & 611 & \\
\hline Skipped question & 6 & \\
\hline $\begin{array}{l}\text { The waiting time to } \\
\text { get the medications }\end{array}$ & $\begin{array}{c}\text { Response } \\
\text { Count }\end{array}$ & $\begin{array}{c}\text { Response } \\
\text { Percent }\end{array}$ \\
\hline$<5$ & 293 & $50.87 \%$ \\
\hline $5-10$ & 188 & $32.64 \%$ \\
\hline $11-15$ & 53 & $9.20 \%$ \\
\hline $16-20$ & 17 & $2.95 \%$ \\
\hline $21-25$ & 4 & $0.69 \%$ \\
\hline $26-30$ & 10 & $1.74 \%$ \\
\hline $31-35$ & 1 & $0.17 \%$ \\
\hline $36-40$ & 2 & $0.35 \%$ \\
\hline $41-45$ & 3 & $0.52 \%$ \\
\hline $46-50$ & 0 & $0.00 \%$ \\
\hline $51-55$ & 1 & $0.17 \%$ \\
\hline $56-60$ & 1 & $0.17 \%$ \\
\hline More than $>60$ & 3 & $0.52 \%$ \\
\hline Answered question & 576 & \\
\hline Skipped question & 41 & \\
\hline
\end{tabular}

Response Response

$43 \quad 18.30 \%$

Response Response
Table 2: The pharmaceutical care services provides to the patients

\begin{tabular}{|l|l|l|}
\hline Answer Options & $\begin{array}{c}\text { Response } \\
\text { Count }\end{array}$ & $\begin{array}{c}\text { Response } \\
\text { Percent }\end{array}$ \\
\hline
\end{tabular}

Medication

consultation

262

Dispensing

of prescribed

medication

$70.78 \%$

Dispensing of

over the counter

medications

$41.56 \%$

Health information

148

consultation

Diseases

consultations

116

Dispensing of

non-medications

233

supplements

$42.29 \%$

Vaccines

23

$4.17 \%$

answered question

551

skipped question 


\begin{tabular}{|c|c|c|c|c|c|c|c|}
\hline Answer Options & Outstanding & Excellent & Neutral & Week & Very weak & Rating Average & $\begin{array}{l}\text { Response } \\
\text { Count }\end{array}$ \\
\hline Pharmaceutical care services at $\mathrm{MOH}$ hospitals & 77 & 183 & 253 & 57 & 27 & 3.38 & 597 \\
\hline $\begin{array}{l}\text { Pharmaceutical care services at non-MOH } \\
\text { governmental hospitals }\end{array}$ & 53 & 199 & 275 & 35 & 24 & 3.38 & 586 \\
\hline Pharmaceutical care services at private hospitals & 113 & 245 & 190 & 28 & 13 & 3.71 & 589 \\
\hline $\begin{array}{l}\text { Pharmaceutical care services at privates primary care } \\
\text { centers }\end{array}$ & 59 & 205 & 250 & 41 & 24 & 3.40 & 579 \\
\hline Pharmaceutical care services at community pharmacies & 78 & 250 & 202 & 27 & 10 & 3.63 & 567 \\
\hline answered question & & & & & & & 601 \\
\hline
\end{tabular}

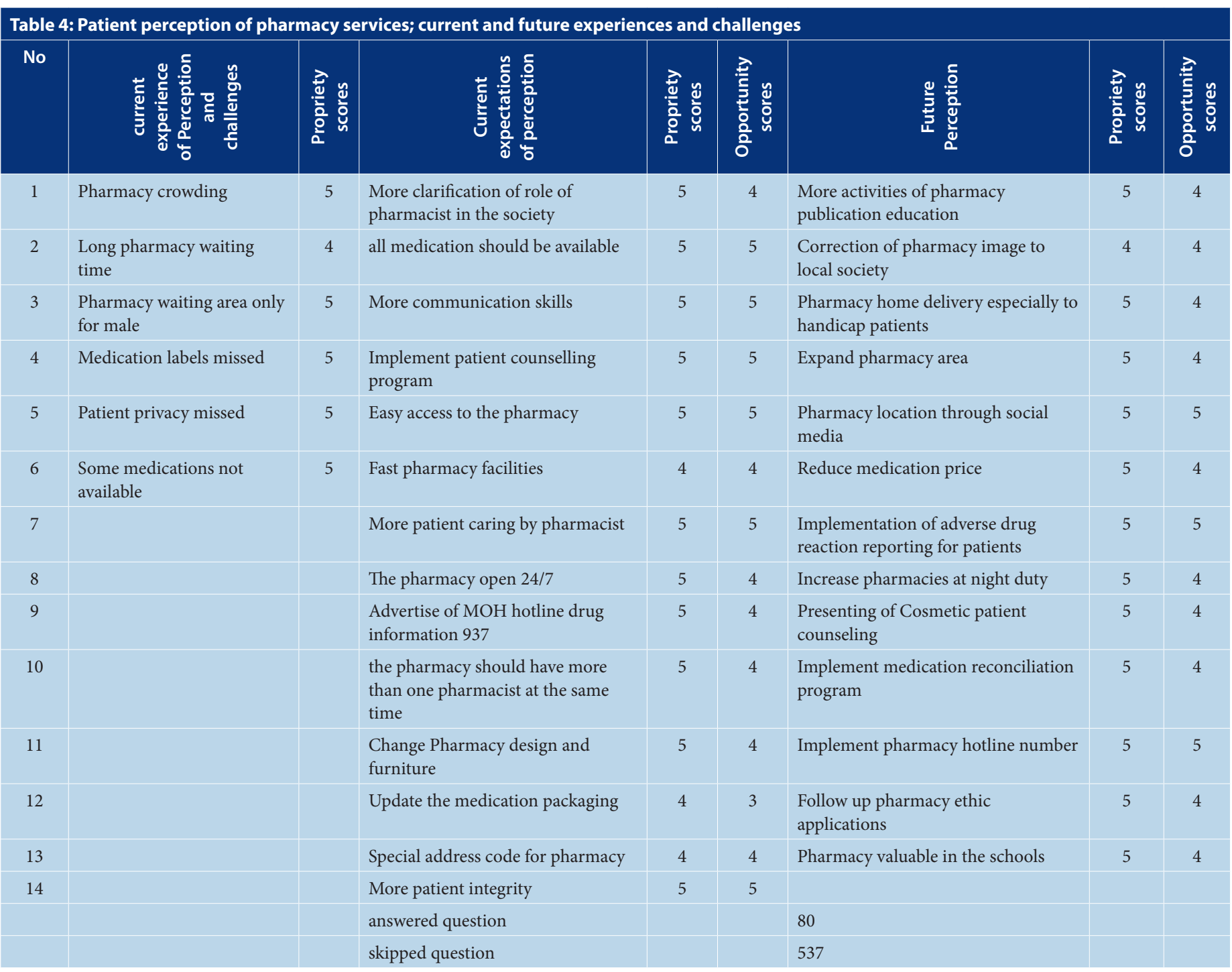

and community pharmacies (3.63) (Table 3). The most current experience of perception and challenges with high propriety scores were some pharmacy crowding, medication labels missed and patient privacy missed. The most current expectations of perception with high propriety and opportunity scores were all medication should be available and implement patient counseling program. The most future perception suggestion with high pro- priety and opportunity scores were published the Pharmacy location through social media and Implementation of adverse drug reaction reporting for patients (Table 4 ). 


\section{DISCUSSION}

The general administration of pharmaceutical care at ministry of health offered several programs to improve pharmacy performance and services. The program direct to a patient, for instance, pain management program, national drug information center, anticoagulation services. ${ }^{[16-18]}$ Also, some pharmacy administration program involved the patient satisfaction and perception of pharmacy services. ${ }^{[19,20]}$ However, this the first study to explore the patient perception of pharmaceutical care services within challenges and development. The finding of the study showed that is the most pharmaceutical care services received by the patient was regular medications or over the counter medications and non-medications, supplements while medications or disease consultation. It resembles what reported by Merks $\mathrm{P}$, et al. ${ }^{[15]}$ That is main most of the pharmacy services not implemented the full concept of pharmaceutical care. Also, the most inferior perception of the services was immunization and vaccines because still not yet approved by the Ministry of Health as pharmacy services through community pharmacies. It resembles what reported by Merks, P et al. ${ }^{[15]}$ The most patient perception level of pharmacy services was in the private sector either hospital or community pharmacies and privates primary care centers. That is maybe related to the comprehensive pharmacy services provided to the patients. While the lowest score of perception of pharmacy services at the governmental hospitals either hospital or primary care centers. That is due to not fully implemented of the pharmacy services and pharmaceuticals care concept. The patients explained the current experience with pharmacy services. The high scores of proprieties were the perception of the crowding of pharmacy, the medication's labels did not exist and the patient privacy missed at most the pharmacies and drugs not available most of the times. All those factors presented in reality at most of the pharmacies. Maybe the implementation of new initiatives of Saudi Managed Care Pharmacy is one the best solution for that. ${ }^{[21]}$ The patient expected to get all medications and implement the patient counseling program. All previous elements found in most of the private hospitals and for that is reasons, most of the patients gave the highest perception of pharmacy services provided by them. The patient expected in the future perceptions with high scores of propriety and opportunities to improve the pharmacy services provided include; the distribution of pharmacy location with their address and services by using social media and application. The new suggestions from the patient in the future that is the pharmacist follow drug therapy and drug-related problems with complete documentation of them. The proposal is potential for implementations to prevent drug misadventures and void the unnecessary the economic burden on the healthcare system in the Kingdom of Saudi Arabia.

\section{CONCLUSION}

Patients' perception is a crucial tool to improve pharmaceutical care. Monitor implementation of the patient medication education system with private places, monitoring of drugrelated problems will support the future vision of patient perception and attitude towards the pharmacist. However, more studies are required to discover further the real reasons behind the absence of pharmaceutical care services in community pharmacies and the best means of addressing this problem.

\section{ACKNOWLEDGEMENT}

KSA: Kingdom of Saudi Arabia; MOH: Ministry of Health; USA: United States of America; CBAHI: Saudi Central Board for Accreditation of Healthcare Institutions; TPN: Total Parenteral Nutrition.

\section{ORCID ID}

Yousef Ahmed Alomi (D) https://orcid. org/0000-0003-1381-628X

\section{REFERENCES}

1. Hepler CD, Strand LM. Opportunities and responsibilities in pharmaceutical care. Am J Hosp Pharm. 1990;47(3):533-43.

2. Alomi YA, Alghamdi SJ, Alattyh RA. Strategic plan of general administration of pharmaceutical care at ministry of health in Saudi Arabia 2012-2022. J Pharm Pharm Scien. 2015;1(3):1-8.

3. Al-Arifi MN, AIDhawailie A, Aldohyan M, Wajid S, Babelgaith SD. A survey on pharmacist opinion about pharmaceutical care in Saudi Arabia. Asian J Pharm. 2015;9(4):277-82.

4. Pedersen CA, Schneider PJ, Scheckelhoff DJ. ASHP national survey of pharmacy practice in hospital settings: prescribing and transcribing-2013. Am J Heal Pharm. 2014;71(11):924-42.

5. Pedersen CA, Schneider PJ, Scheckelhoff DJ. ASHP national survey of pharmacy practice in hospital settings: Monitoring and patient education-2015. Am J Heal Pharm. 2016;73(17):1307-30

6. Alsultan MS, Mayet AY, Khurshid F, Al-Jedai $A H$. Hospital pharmacy practice in Saudi Arabia: drug monitoring and patient education in the Riyadh region. Saudi Pharm J. 2013;21(4):361-70.

7. Alsultan MS, Khurshid F, Mayet AY, Al-Jedai AH. Hospital pharmacy practice in Saudi Arabia: Dispensing and administration in the Riyadh region. Saudi Pharm J. 2012;20(4):307-15.

8. Ahmed Alomi Y, Jamaan Alghamdi S, Abdullah Alattyh R, Shorog E, Alshahran A, Alasmary S, et al. National Survey of Pharmacy Practice at $\mathrm{MOH}$ Hospitals in Saudi Arabia 2016-2017: Pharmacy Management and Resource. J Pharm Pract Community Med. 2018;4(1S):S1-S16.

9. Merks P, Świeczkowski D, Jaguszewski MJ. Patients' perception of pharmaceutical services available in a community pharmacy among patients living in a rural area of the United Kingdom. Pharm Pract. 2016;14(3):774.

10. Khan MU, Khan AN, Ahmed FR, Feroz Z, Rizvi SA, Shah S, et al. Patients' opinion of pharmacists and their roles in health care system in Pakistan. J Young Pharm. 2013;5(3):90-4

11. Oshima S, Senoo K, Negishi A, Akimoto H, Kutsuma $\mathrm{N}$, Juni $\mathrm{K}$, et al. Identification of the discrepancies between pharmacist and patient perception of the pharmacist's role as an advisor on drug therapy based on social science theory. Biol Pharm Bull. 2016;39(39):313-22.

12. The Joint Commission. Comprehensive Accreditation Manuals. Joint Commission Resources. Available from: http://www.jcrinc.com/store/publications/manuals/.

13. Medication Management (MM). In: National Hospital Standards. 2nd Edition. Saudi Central Board for Accreditation of Healthcare Institutions, 2015;194-211. Available from: http://www.cbahi. gov.sa.

14. Alomi YA, Kurdy L, Aljarad Z, Basudan H, Almekwar B, Almahmood S. Patient satisfaction of pharmaceutical care of primary care centers at ministry of health in Saudi Arabia. J Pharm Pract Community Med. 2016;2(3):79-87.

15. Merks P, świeczkowski D, Jaguszewski MJ. Patients' perception of pharmaceutical services available in a community pharmacy among paᄀtients living in a rural area of the United Kingdom. Pharm Pract. 2016;14(3):774.

16. Alomi YA. National pharmacy pain management program at ministry of health in Saudi Arabia. J Pharmacol Clin Res. 2017;3(2):001-7.

17. Alomi YA. National drug information center program at ministry of health in Saudi Arabia. Adv Pharmacoepidemiol Drug Saf. 2016;5(5):1-2

18. Alomi YA. National pharmacy anticoagulation program at ministry of health in Saudi Arabia. BAOJ Pharm Sci. 2017;3(3):3-7.

19. Alomi YA. National Pharmacy Administration Programs at ministry of health in Saudi Arabia. BAOJ Pharm Sci. 2015;1(9).

20. Alomi YA. Patient satisfaction of pharmaceutical care system at ministry of health in Saudi Arabia. BAOJ Pharm Sci. 2016;2(1):19

21. Alomi YA, Alghamdi SJ, Alattyh RA. Saudi Managed Care Pharmacy (SMCP): New initiative system of $\mathrm{MOH}$ prescriptions dispensed through community pharmacies. J Pharm Pract Community Med. 2017;3(3):145-53. 